\title{
The Study of Correlation between Online English Learning Anxiety and Achievement for Chinese College Students
}

\author{
Yongjin Zhu' ${ }^{1}$, Haitao Qin $^{1}$, Chi Chen ${ }^{1}$, Li Duan ${ }^{1}$ \\ ${ }^{1}$ College of Foreign Studies, Hubei Normal University, Huangshi, Hubei, China \\ azyj1149@126.com
}

Keywords: online English learning anxiety; achievement; chinese College students

\begin{abstract}
The popularization of mobile internet devices is the foundation of the reformation in foreign language learning learning mode. And studies on online foreign language learning anxiety has been the hot topic recently. This thesis applied Foreign Language Classroom Anxiety Scale to explore the relationship between online English learning anxiety and achievement. And the results demonstrated that Chinese college students are showing moderate English learning anxiety. Online English learning anxiety is negatively correlated with language achievement. It worth noting that there exist significant differences between female and male students towards detailed elements in language anxiety scale.
\end{abstract}

\section{Introduction}

The existence of Internet has dramatically changed the way people communicate and contact with others, as well as the way people live, work, and study. Traditional second language teaching and learning are totally based on the classroom input, in which students are passive recipients without much reasonably effective interaction with teachers or classmates. And previous studies show that language learning ability and motivation are negatively influenced by such environment,thus arousing negative feelings, such as anxiety, frustration, self-consciousness, or fear. While the popularization and application of Internet makes it possible for Chinese learners to learn English online which is quiet different from traditional learning experience. However, under the environment of online English learning, whether the language learning anxiety standard will be relatively stable or significantly changed still needs experimentation.

Anxiety is the subjective feeling of tension, apprehension, nervousness, and worry associated with an arousal of the autonomic nervous system (Spielberger, 1983). It is an important emotional factor that influence language learning process, some scholars believe that anxiety, as the stimulus to arouse attention, facilitates language learning (Alpert \& Haber call it the facilitating anxiety). However, high level of anxiety causes vicious circle on language acquisition. Just as anxiety impedes people's normal performance in many aspects of life, when it is concerned with language learning situation, it means specific anxiety reactions, thus the term "Foreign Language Anxiety" is putting forward (Horwitz, 1986). Previous studies have proven that difficulty in communication, test anxiety, fear of negative evaluation are blocking people from better behaving themselves, however, the combination of fears is not simply equivalent to the foreign language anxiety. Horwitz, Horwitz, and Cope demonstrated foreign language anxiety as a distinct complex of self-perceptions, beliefs, feelings, and behaviors related to classroom language learning process (Horwitz \& Horwitz \& Cope, 1986).

The trend of globalization makes English learning more and more universal, almost every country is learning English as their foreign language. As a consequence, more and more English learners show excessive language learning anxiety, at the meantime, researchers of second language acquisition are paying more attention to the existence of anxiety in recent years. There have been numerous researches on the relationship between foreign language anxiety and achievement. And with the rising application of computer-assisted language learning, online English learning is a prevailing tendency as a convenient and efficient method for English learners. Most previous studies 
are focusing on the traditional foreign language learning environment, however, few researches are specific to the relationship between current online English learning and achievement.

\section{Purpose of the Study}

This study aims to find out the correlation between current online English learning anxiety and achievement for college students subjects . And it aims to answer the following question:

What is the level of online English learning anxiety for non-English majors?

To what extent do students perceive that online English learning anxiety affects English Achievement?

What are the major sources to cause online English learning anxiety?

\section{Methodology}

Participants. The participants are 196 sophomore from a normal university ranging from 18 to 20, most of them have been learning English for more than 7 years. All of them are familiar with the online learning.

Instrument. The Foreign Language Classroom Anxiety Scale was designed by Horwitz,(1986). The author revised the FLCAS to fit the online environment and it consists of 33 statements as for comprehensive anxiety, communication apprehension anxiety, fear of negative evaluation , test anxiety, Internet anxiety. The FLCAS was scored by 5-point Likert Sclae ,with 33 points to 165 points . The higher point is, the heavier the students have the anxiety. The Cronbach's alpha of this questionnaire is 0.746 .

Students' language achievement comes from the College English Test - 4, which are standardized scores.

Procedures. The students have one year of online English experiences of College English twice a week. All the questionnaires were delivered to students to make their choices and collected after 45 minutes.All the data were put into SPSS .19 to analyze.

\section{Results and Discussion}

The level of online English learning anxiety for non-English majors

Table 1 Mean and Deviation of Online Foreign Language Classroom Anxiety

\begin{tabular}{l|c|c|c|c|c}
\hline & $\mathrm{N}$ & Minimum & Maximum & Mean & Std. Deviation \\
\hline Total (FLCAS) & 196 & 64 & 128 & 97.64 & 10.985 \\
\hline Average (FLCAS) & 196 & 1.94 & 3.88 & 2.9589 & .33287 \\
\hline
\end{tabular}

The table shows that the mean value for overall learner anxiety is 2.96 , which is lower than the average $(M=3.00)$. .This result is similar to other studies (Shi,2006; Huang,2009; Zeng,2012; Zhu,2014).It shows that objective existence of language anxiety phenomenon and the anxiety phenomenon is still with foreign language learning process. The Std. Deviation with 0.33287 shows the decrease of the internal diversity between individuals of language learning anxiety. Broadly speaking, English learning anxiety level in college students is generally declining, this means that online language learning environment and multimedia environment is conducive to alleviate the anxiety. And it also proved that current multimedia environment meets the demands of foreign language learning. 


\section{The Correlation Between Online English Learning Anxiety And Achievement}

Table 2 Correlation between Online English Learning Anxiety and CET Score

\begin{tabular}{c|c|c|c}
\hline \multicolumn{2}{c|}{} & FLCAS & CET-4 \\
\hline \multirow{3}{*}{ Total score of anxiety } & Pearson Correlation & 1 & $-.149^{*}$ \\
\cline { 2 - 4 } & Sig. (2-tailed) & & .038 \\
\cline { 2 - 4 } & $\mathrm{N}$ & 196 & 1 \\
\hline \multirow{2}{*}{ CET-4 score } & Pearson Correlation & $-.149^{*}$ & 196 \\
\cline { 2 - 4 } & Sig. (2-tailed) & .038 & 196 \\
\cline { 2 - 4 } & $*$ N & 196 & \\
\hline
\end{tabular}

From table 2, it can be found that $\mathrm{r}=\mathrm{-} .149^{*}$, which demonstrated a small negative correlation but at a non-significant level between online English learning anxiety and achievement. This result is generally similar to previous studies for different students (Zou , 2003; Fan, 2000; Seller 2000; Young (2000). The popularization and application of Internet and computer-assisted multimedia learning may be the key to explain current report result. In an era of Internet and information, and artificial intelligence is accessible to most people, especially college students who are supposed to equip the ability to accept new things, it is inevitable that English learning environment has changed. The subjects of this study have been exposed to the multimedia classroom since they were middle school students. This may make them get accustomed to the online English learning. It also can be concluded that college students are more inclined to use mobile devices and network devices while learn a second language.

\section{Major sources of online English learning anxiety}

Table 3 Descriptive Statistics of FLCAS in Descending Order

\begin{tabular}{|c|c|c|c|}
\hline & & Mean & SD \\
\hline 7 & I feel depressed when I make too many mistakes in reading training. & 3.64 & 1.080 \\
\hline 6 & $\begin{array}{l}\text { I feel uneasy and anxious when I can't finish reading exercise within the stipulated } \\
\text { time. }\end{array}$ & 3.56 & 1.068 \\
\hline 15 & $\begin{array}{l}\text { I am afraid of speaking out in multimedia class, and I fear that I can’t express } \\
\text { myself clearly. }\end{array}$ & 3.54 & .891 \\
\hline 2 & I feel upset when I can’t focus on finishing listening test. & 3.52 & 1.020 \\
\hline 21 & I can feel my heart pounding when I am going to be called on English class. & 3.43 & 1.013 \\
\hline 9 & I feel overwhelmed by the number of rules you have to learn to speak English. & 3.42 & 1.076 \\
\hline 24 & $\begin{array}{l}\text { I don't feel anxious about an English test failure because of diversified comment } \\
\text { forms. }\end{array}$ & 3.33 & 1.046 \\
\hline 20 & I keep thinking that the other students are better at English than I am. & 3.32 & 1.015 \\
\hline 8 & $\begin{array}{l}\text { I can't help peeking the model answer while doing online writing training, and I } \\
\text { feel frustrated when my thoughts are far away from the answers. }\end{array}$ & 3.29 & 1.086 \\
\hline 32 & The overwhelmed network information increases the difficulty to choose. & 3.27 & 1.116 \\
\hline 31 & $\begin{array}{l}\text { Sometimes, I can’t complete autonomous English learning task because of slow } \\
\text { network speed. }\end{array}$ & 3.21 & 1.106 \\
\hline
\end{tabular}




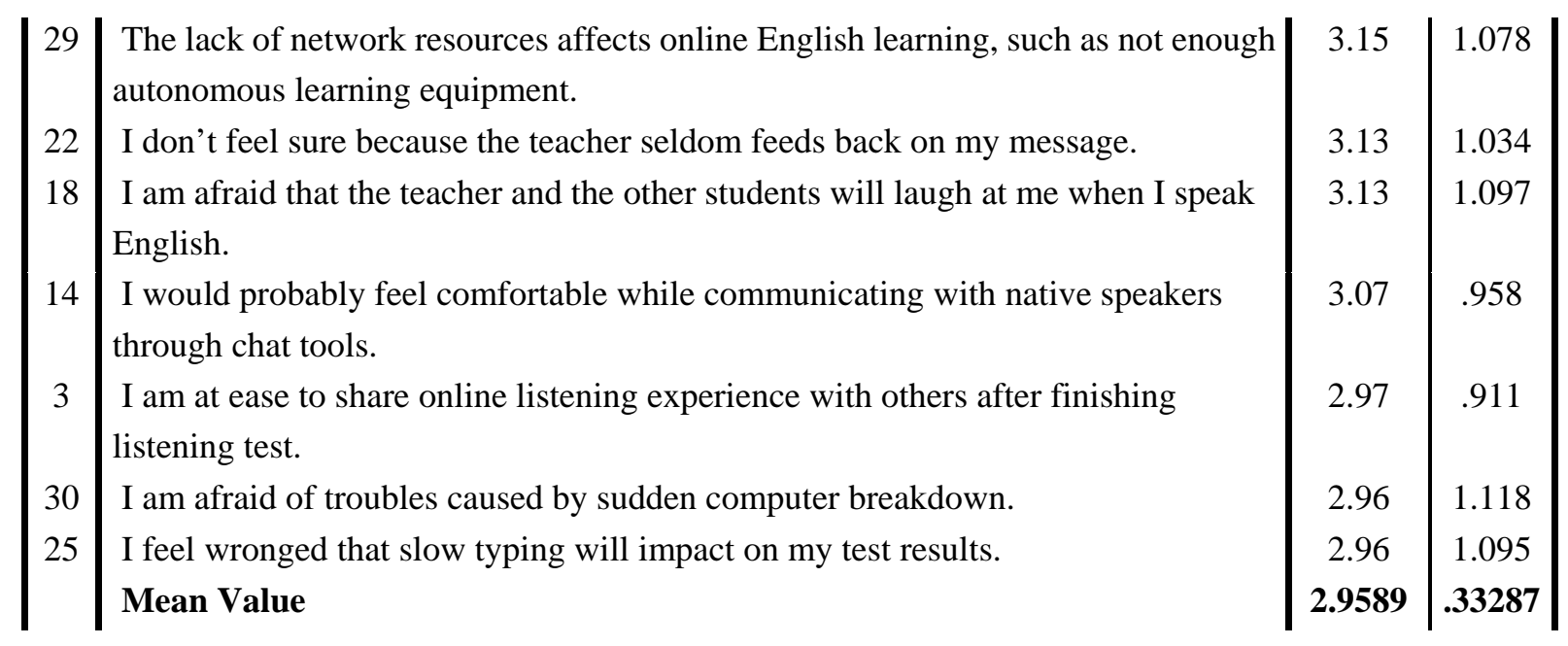

The first cause is concerned with comprehensive anxiety. Item 7, item 6, they are reflection language learning anxiety during English learning process from different aspects. Furthermore, six out of nine statements (item 2, 3, 6, 7, 8, 9) are concerned with comprehensive anxiety. The conclusion can be drawn that whether it is under traditional classroom environment or online learning environment, it is a great challenge for sophomore students to have comprehensive assessment on their performance in listening, speaking, reading, and writing. Thus, students are still showing excessive anxiety towards online learning.

The second main reason is the fear of negative evaluation. Item 21, 20, 18. Students are terrified of being negatively evaluated by others whether the evaluation behavior really happens. Meanwhile, they are afraid of being less competent than other students.

The third major reason is Internet anxiety which can be found from statement 32, 31, 29, 30, 32.The lack of network resources ,such as not enough autonomous learning equipment, as well as sudden computer breakdown are all anxiety-provoking causes. Online English learning environment requires learners to finish assignment and get information by themselves, however, even if Internet has brought great convenience, the vast resources of information makes it difficult to make choice. And from the other side, the immaturity of online language learning needs improvement. The subjective feeling of English learning is something that can not be changed easily, but providing relaxing, appropriate learning environment; offering direct, effective instruction, and complete equipment can be helpful and useful for language learners.

\section{Conclusion}

Tthis study figured out that Online English learning anxiety of college students is negatively correlated with language achievement. And online English learning environment can be conducive to reduce language learning anxiety. A conclusion can be drawn that there are many different factors with influences on foreign language learning anxiety.

\section{References}

[1] Huang, P. W. An Exploration of EFL Learners’ Anxiety and E-learning Environments . Journal of Language Teaching and Research, 2013, 4 (1):27-34.

[2] Hwang, Y. L. , \& Huang, P. W. A Study of EFL College Students' Language Anxiety in Multimedia Environments . The International Journal of the Humanities, 2010, 8 (2): 367-378.

[3 Horwitz, E. K. Language Anxiety and Achievement , Annual Review of Replied Linguistics, 2001, 21: $112-126$. 
[4] Horwitz, E. K. , Horwitz, M. B. , \& Cope, J. Foreign Language Classroom Anxiety [J]. The Modern Language Journal, 1986, 70 (2): 125-132.

[5] Xiong Suchun, The Study of Relation between Foreign Language Learning Anxiety and Learning Strategies Use. Journal of Computer Assisted Foreign Language Education 2012, 148: 66-71.

[6] Zou Yanying. A Study of the Relationships Among Foreign Language Anxiety, Language Learning Strategy Use, and Foreign Language Achievement. Master 's Thesis of South China Normal University, 2003: 69-71. 